DOI: 10.4274/jarem.galenos.2019.2771

J Acad Res Med 2020; 10(1): 75-81

\title{
Outcomes of Post-traumatic Stiff Elbow Arthrolysis
}

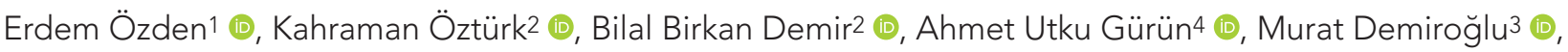 \\ Serkan Aykut² \\ ${ }^{1}$ University of Health Sciences Turkey, Gaziosmanpaşa Training and Research Hospital, Clinic of Orthopedics and Traumatology, İstanbul, \\ Turkey \\ ${ }^{2}$ Istanbul Baltalimanı Metin Sabancı Bone Diseases Training and Research Hospital, Clinic of Hand and Upper Extremity Surgery, İstanbul, \\ Turkey \\ ${ }^{3}$ istanbul Medeniyet University Göztepe Training and Research Hospital, Clinic of Orthopedics and Traumatology, İstanbul, Turkey \\ ${ }^{4}$ İstanbul Bağcılar Training and Research Hospital, Clinic of Orthopedics and Traumatology, İstanbul, Turkey
}

Cite this article as: Özden E, Öztürk K, Demir BB, Gürün AU, Demiroğlu M, Aykut S. Outcomes of Post-traumatic Stiff Elbow Arthrolysis. JAREM 2020;10(1): 75-81

\begin{abstract}
Objective: In this study, the results of open release surgeries performed for the stiff elbows which were caused by intrinsic, extrinsic or by combination of both factors were evaluated.

Methods: Twenty-three elbows of 22 patients who could not perform functional elbow motions were surgically treated between January 2005 and December 2012. The mean age was 30.6 \pm 11.4 years ( 16 to 67 years), and the average follow-up period was 81 months (58 months to 12 years). Elbow arc of motions was recorded pre- and postoperatively. Patients were evaluated clinically by using quick Disabilities of the Arm, Shoulder and Hand (DASH) self-report questionnaire, and MAYO elbow performance scores.

Results: The mean preoperative elbow arc of motion was 42 degrees (0-90), and it became 109 degrees (70-140) postoperatively after at least 58-month follow-up. The average increase was $67.8 \pm 25$ degrees (30-125). The mean Quick DASH score was $18.2 \pm 12.7$ (6.8 to 63.6). According to MAYO elbow rating system, one patient who had experienced infection following the initial fracture treatment had poor result, three patients had fair results, 17 patients had good results, and one patient who had bilateral elbow stiffness had excellent results.

Conclusion: Although good results can be achieved by open release of the stiff elbows, one must keep in mind that preventing the stiffness rather than solving this problem would bring better results. As 15 patients with stiff elbows in this study had a previous surgery performed for an elbow region fracture, stabile fixation, meticulous hemostasis, shorter immobilization period and early rehabilitation can be considered as the most important steps for avoiding elbow stiffness where surgery is indicated.
\end{abstract}

Keywords: Elbow, stiff, arthrolysis, post-traumatic

\section{INTRODUCTION}

The elbow joint is very congruent with three articulations: the ulnohumeral joint, the radiocapitellar joint, and the proximal radioulnar joint. The stability of the elbow is provided by static and dynamic stabilizers. The ulnohumeral articulation, the anterior bundle of the medial collateral ligament, and the lateral collateral ligament complex are acting as the primary static constraints, and the radiocapitellar articulation, the common flexor tendon, the common extensor tendon, and the capsule are acting as secondary static constraints. The dynamic stabilizers are the muscles crossing the elbow (1-3).

Morrey et al. (1) pointed out that 30 to 130 degrees of flexion with 50 degrees pronation and 50 degrees supination may provide

ORCID IDs of the authors: E.Ö. 0000-0003-0765-5635; K.Ö. 0000-0002-7644-659X; B.B.D. 0000-0003-3449-3870; A.U.G. 0000-0001-5326-7161;

M.D. 0000-0001-7992-2662; S.A. 0000-0003-1028-2120. 
a functional range of motion (ROM) for most of the daily living activities. We may call the elbow "stiff" if the hand cannot be used functionally due to the loss of elbow motion and this functionality differs for each individual.

The etiology of elbow stiffness must be well understood while planning the treatment. Anatomically the reasons can be classified as extrinsic, intrinsic or combination of both. The intrinsic contracture term is used to determine that the pathology involves the articular surface such as articular adhesions, arthritis, osteophytes, loose bodies, malunions of intra-articular fractures and proliferative synovitis. The extrinsic contracture term defines the periarticular pathologies such as capsule, ligaments, muscles and skin contractures surrounding the joint and also the heterotopic bone formation within these structures. The most common type of elbow contracture is the post-traumatic stiff elbow which usually involves both of the intrinsic and extrinsic pathologies $(4,5)$.

The conservative treatment of stiff elbow includes therapeutic heat application, myofascial soft tissue mobilization, progressive ROM exercises and contracture splinting. Surgery is considered when conservative treatments fail. Surgical treatment options have a spectrum from arthroscopic or open anterior and posterior capsular release to total elbow arthroplasty $(6,7)$. Molecular pathogenesis of the stiffness is still under investigation and immunohistochemical studies warrants further investigation $(8,9)$.

The purpose of this study is to report the functional outcome of the surgically treated stiff elbows.

\section{METHODS}

We reviewed 23 stiff elbows of 22 patients who underwent surgical release between January 2005 and December 2012. Conservative treatment methods were tried for at least six months for all of the patients. Surgery was considered for the patients who could not perform functional elbow motions and did not respond to conservative treatment methods. Plain radiographs were obtained to assess the heterotopic bone formations, articular surfaces, hardware positions and the healing of initial fractures. Computerized tomography (CT) scans were also obtained before the treatment to evaluate the articular surfaces more accurately.

The mean age of the patients was $30.6 \pm 11.4$ years ( 16 to 67 years), six of the patients were female and 16 were male. The average follow-up period was 81 months (58 months to 12 years). Elbow arc of motions was recorded preoperatively and postoperatively. Patients were evaluated clinically by using quick Disabilities of the Arm, Shoulder and Hand (DASH) self-report questionnaire, and MAYO elbow performance scores.

Only post-traumatic stiff elbows were included in this study; nine patients experienced radial head fractures, four patients had complex elbow fractures (humerus lower end fracture dislocation accompanying ulna or radius fractures), four patients had humerus lower end fractures, three elbows of two patients had heterotopic ossification ( $\mathrm{HO}$ ) due to head and elbow trauma, one patient had olecranon fracture, one patient had radial head chronic luxation, and one patient had radial head fracture with humeroulnar luxation. Fifteen patients with fractures underwent surgical intervention after the fractures occurred. The mean time elapsed from the initial trauma to surgical release was 21.4 months. No joint instability was observed before and after the treatment. The etiologies of the stiffness were also demonstrated in Table 1.

All surgical arthrolyses were performed by one of the senior hand and upper extremity surgeon at the author's clinic.

All surgeries were performed under regional block anesthesia and indwelling brachial plexus catheters were placed for postoperative pain management. Lateral incisions alone were used in eleven patients, medial incisions alone in four patients, single anterior incisions in three elbows of two patients, medial and lateral incisions were combined in four patients, and a single posterior incision was used for one patient. Anterior capsulectomy (Figure 1) was performed for extension deficit and posterior capsulectomy (Figure 2) was performed to gain flexion (Figure 3 , 4). Additionally, radial head excision was also performed for four patients, $\mathrm{HO}$ excision for three elbows of two patients, radial head prosthesis excision for three patients, nervus ulnaris anterior transposition (Figure 1) for four patients and nervus ulnaris release for five patients. After soft tissue and heterotopic bone excisions, olecranon fossa and the coronoid fossa were explored to check if any osteophytes or callus formation making a mechanical block remained. If the extension block was due to posterior impingement, widening the olecranon fossa by the help of a high-speed burr and also the excision of the tip of the olecranon while preserving the triceps tendon insertion were generally needed. If there was any hardware to be removed, the removal was performed at the end of the operations. The tourniquets were released, surgical hemostasis was achieved by cauterization. After applying closed suction drainage, skin closures were performed. The degree of flexion/extension and also supination/pronation achieved under anesthesia were measured and noted. The elbow was usually splinted in maximal extension, but if the patient was suffering only for lack of flexion and already had full extension before the operative release, the elbow was splinted in maximal flexion for 24 hours. Progressive passive ROM exercises was started in the following day and the drains were left in place until the drainage stopped, which was usually observed in the third day after surgery. Patients received a therapy program immediately after discharge.

Patients' data were collected with permission, by reviewing the medical records. This study was conducted in accordance with the Declaration of Helsinki. Ethics committee approval was received for this study from the ethics committee of University of Health Sciences Turkey, Gaziosmanpaşa Training and Research Hospital (approval number: 125; date: 16.01.2019). Informed consent was obtained. 
Table 1. Patient's descriptive data

\begin{tabular}{|c|c|c|c|c|c|c|c|c|c|c|c|}
\hline Patient No & $\begin{array}{l}\text { Age, y } \\
\text { Sex side }\end{array}$ & $\begin{array}{l}\text { Pre-op flex/ } \\
\text { ext sup/pron }\end{array}$ & $\begin{array}{l}\text { Post-op } \\
\text { final flex/ } \\
\text { ext sup/ } \\
\text { pron }\end{array}$ & $\begin{array}{l}\text { Gained arc } \\
\text { of motion } \\
\text { (flex/ext) }\end{array}$ & Approach & Etiology & $\begin{array}{l}\text { Pre-op. } \\
\text { ulnar } \\
\text { neuropathy }\end{array}$ & $\begin{array}{l}\text { DASH } \\
\text { score } \\
\text { pre-op }\end{array}$ & $\begin{array}{l}\text { DASH } \\
\text { scores } \\
\text { post-op }\end{array}$ & $\begin{array}{l}\text { MAYO } \\
\text { scores } \\
\text { Pre-op }\end{array}$ & $\begin{array}{l}\text { MAYO } \\
\text { scores } \\
\text { post-op }\end{array}$ \\
\hline 1 & 40/M/right & $140 /-50$ & 150/-10 & 50 & Lateral & $\begin{array}{l}\text { Radial head } \\
\text { fracture }\end{array}$ & - & 50 & 20.50 & 70 & 85 \\
\hline $\begin{array}{l}\text { Left elbow } \\
\text { of } 2\end{array}$ & 16/M & $90 /-40$ & $130 / 0$ & 80 & Anterior & $\begin{array}{l}\text { Myositis } \\
\text { ossificans }\end{array}$ & - & 56.8 & 27.3 & 60 & 100 \\
\hline $\begin{array}{l}\text { Right } \\
\text { elbow of } 2\end{array}$ & - & $\begin{array}{l}\text { 60/no motion } \\
\text { (ankylosis) }\end{array}$ & $130 /-10$ & 120 & Anterior & $\begin{array}{l}\text { Myositis } \\
\text { ossificans }\end{array}$ & - & 61.4 & 6.8 & 50 & 100 \\
\hline 3 & 27/F/left & $80 /-30$ & 130/-10 & 70 & Medial & $\begin{array}{l}\text { Radial head } \\
\text { fracture }\end{array}$ & + & 54.5 & 20.50 & 55 & 85 \\
\hline 4 & 25/M/left & $90 /-40$ & 110/-25 & 35 & Lateral & $\begin{array}{l}\text { Radial head } \\
+ \text { capitellum } \\
\text { fracture }\end{array}$ & - & 61.4 & 34.10 & 50 & 65 \\
\hline 5 & 35/M/right & $90 /-45$ & 110/0 & 65 & $\begin{array}{l}\text { Lateral + } \\
\text { Medial }\end{array}$ & $\begin{array}{l}\text { Complex } \\
\text { elbow fracture }\end{array}$ & + & 65.9 & 15.90 & 50 & 85 \\
\hline 6 & 44/M/left & $90 /-40$ & 130/-20 & 60 & Medial & $\begin{array}{l}\text { Humerus lower } \\
\text { end fracture }\end{array}$ & - & 63.6 & 13.6 & 50 & 85 \\
\hline 7 & 35/M/left & $60 /-40$ & 80 / -10 & 50 & Lateral & $\begin{array}{l}\text { Radial head } \\
\& \text { coronoid } \\
\text { fracture }\end{array}$ & - & 81.8 & 63.6 & 30 & 50 \\
\hline 8 & 16/M/right & 120/-55 & $130 /-10$ & 55 & $\begin{array}{l}\text { Lateral + } \\
\text { Medial }\end{array}$ & $\begin{array}{l}\text { Humerus lower } \\
\text { end fracture }\end{array}$ & - & 68.2 & 6.8 & 65 & 85 \\
\hline 9 & $36 / \mathrm{M} /$ right & 110/-40 & $135 /-10$ & 55 & Medial & $\begin{array}{l}\text { Olecranon } \\
\text { fracture }\end{array}$ & - & 65.9 & 22.7 & 70 & 85 \\
\hline 10 & 29/M/right & $70 /-40$ & 130/-10 & 90 & Lateral & $\begin{array}{l}\text { Radial head } \\
\text { fracture }\end{array}$ & - & 70.5 & 11.4 & 50 & 85 \\
\hline 11 & 26/M/left & $100 /-60$ & 100/-30 & 30 & Lateral & $\begin{array}{l}\text { Complex } \\
\text { elbow fracture }\end{array}$ & - & 77.3 & 31.8 & 40 & 60 \\
\hline 12 & 32/F/right & $90 /-70$ & $120 /-40$ & 60 & Posterior & $\begin{array}{l}\text { Complex } \\
\text { elbow fracture }\end{array}$ & - & 77.3 & 29.50 & 40 & 60 \\
\hline 13 & 24/M/right & $120 /-45$ & $135 /-20$ & 40 & $\begin{array}{l}\text { Lateral + } \\
\text { Medial }\end{array}$ & $\begin{array}{l}\text { Radial head } \\
\text { fracture }\end{array}$ & - & 63.6 & 11.4 & 55 & 85 \\
\hline 14 & 20/M/left & $80 /-45$ & 120/-20 & 65 & Lateral & $\begin{array}{l}\text { Humerus lower } \\
\text { end fracture }\end{array}$ & - & 70.5 & 13.6 & 50 & 85 \\
\hline 15 & 47/F/right & 110/-50 & 130/-20 & 50 & Lateral & $\begin{array}{l}\text { Radial head } \\
\text { fracture }\end{array}$ & - & 63.6 & 11.4 & 50 & 85 \\
\hline 16 & 24/F/right & $\begin{array}{l}\text { Fixed at } \\
90 \text { degree } \\
\text { flexion }\end{array}$ & 135/-20 & 115 & Anterior & $\begin{array}{l}\text { Myositis } \\
\text { ossificans }\end{array}$ & - & 77.3 & 13.6 & 45 & 85 \\
\hline 17 & 32/F/right & $\begin{array}{l}\text { Fixed at } \\
90 \text { degree } \\
\text { flexion }\end{array}$ & $135 /-10$ & 125 & $\begin{array}{l}\text { Lateral + } \\
\text { Medial }\end{array}$ & $\begin{array}{l}\text { Humerus lower } \\
\text { end fracture }\end{array}$ & + & 79.5 & 11.4 & 45 & 85 \\
\hline 18 & $67 / \mathrm{M} /$ right & $90 /-45$ & $140 /-20$ & 75 & Medial & $\begin{array}{l}\text { Radial head } \\
\text { fracture + } \\
\text { humero-ulnar } \\
\text { luxation }\end{array}$ & + & 81.8 & 9.1 & 45 & 85 \\
\hline 19 & 28/M/left & $90 /-60$ & $120 /-30$ & 60 & Lateral & $\begin{array}{l}\text { Radial head } \\
\text { fracture }\end{array}$ & - & 79.5 & 13.6 & 45 & 80 \\
\hline 20 & 31/F/right & $80 /-40$ & 130/-20 & 70 & Lateral & $\begin{array}{l}\text { Radial head } \\
\text { chronic } \\
\text { luxation }\end{array}$ & - & 77.3 & 15.9 & 50 & 80 \\
\hline 21 & 30/M/right & 100/-50 & $140 /-20$ & 70 & Lateral & $\begin{array}{l}\text { Radial head } \\
\text { fracture }\end{array}$ & - & 50 & 6.8 & 50 & 85 \\
\hline 22 & 24/M/left & 110/-50 & $130 /-20$ & 70 & Lateral & $\begin{array}{l}\text { Complex } \\
\text { elbow fracture }\end{array}$ & - & 56.8 & 9.1 & 55 & 85 \\
\hline
\end{tabular}




\section{Statistical Analysis}

We have compared the preoperative and post-operative flexion and extension degrees, DASH scores, and the MAYO elbow performance scores with the Wilcoxon rank-sum test by using SPSS 22.0 (SPSS Inc, IBM, Chicago, IL) software. P-values less than 0.05 were regarded as statistically significant.

\section{RESULTS}

The mean preoperative elbow flexion was $93.4 \pm 19$ degrees (ranges from 60 to 140 degrees) and lack of extension was $51 \pm 15.2$ degrees (30 to 90 degrees). The average postoperative flexion of elbow was $126 \pm 14.8$ degrees (80 to 150 degrees) and lack of extension was $17 \pm 9.4$ degrees ( 0 to 40 degrees) after a mean follow-up period of 81 months. Preoperative mean arc of motion was 42 degrees ( 0 to 90 degrees), and it became 109.3 degrees (70 to 140 degrees) postoperatively after at least 58-month follow-up. The average increase was 67.8 24.9 degrees (30-125 degrees). The preoperative mean Quick DASH score was $69 \pm 9$ points, and it was calculated as $18.2 \pm 12.7$ (6.8 to 63.6 ) at the last visit. These changes were found statistically significant. According to MAYO elbow rating system, one patient who had experienced infection following the initial surgery for the fracture treatment had poor results, three patients had fair results, 17 patients had good results, and one patient had excellent results for both of his elbows. Ulnar nerve related symptoms of four patients were recovered after anterior transposition of the nerves. No infection, instability or recurrence of $\mathrm{HO}$ was observed after the releases.

\section{DISCUSSION}

In this study, we described our experience in surgical release of stiff elbows. Before deciding surgical intervention to release the contracture, the pathology and also the expectations of the patient must be well understood and the patient must be aware of the risks of the procedure such as pain, instability, weakness and worsening of the ulnar nerve related symptoms.

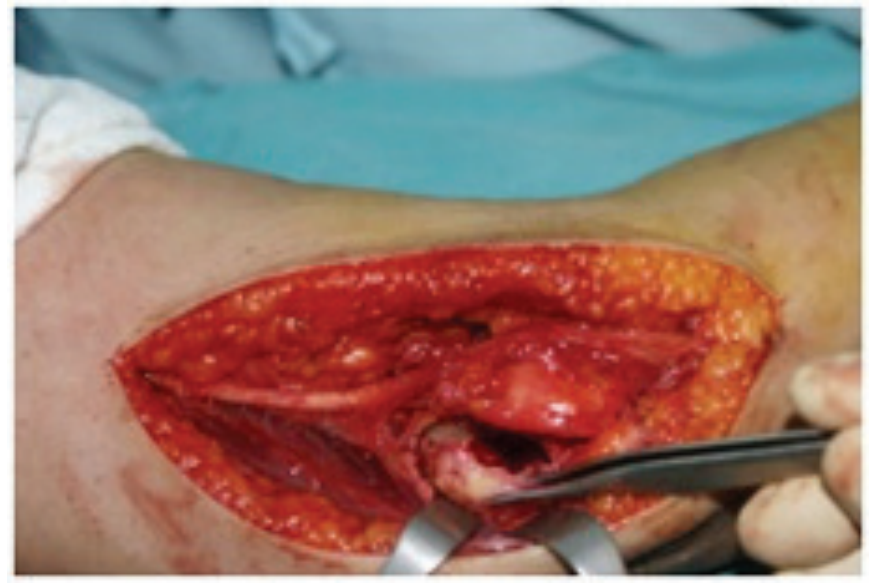

Figure 1. Posterior capsular excision by using the "medial over the top" technique

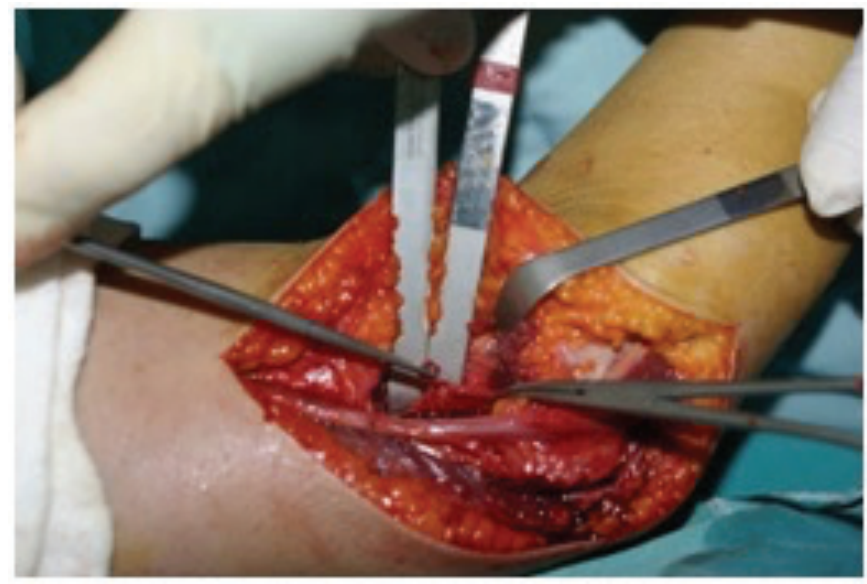

Figure 2. Anterior capsular excision

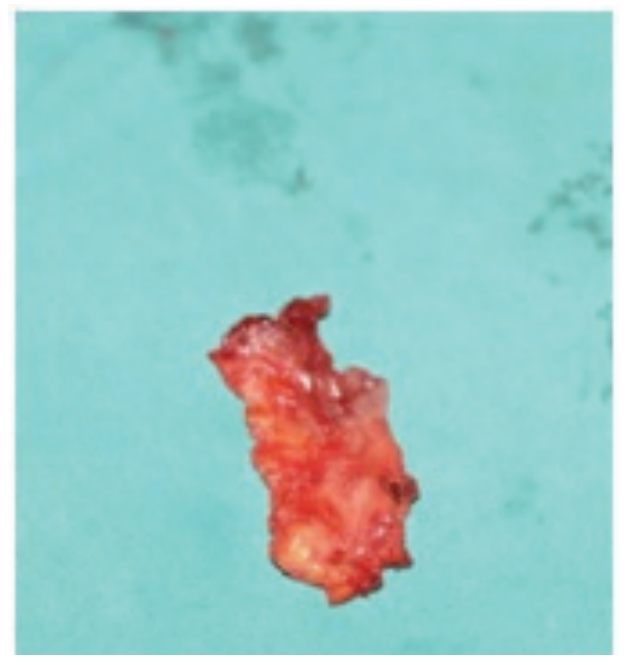

Figure 3. Excised posterior capsule

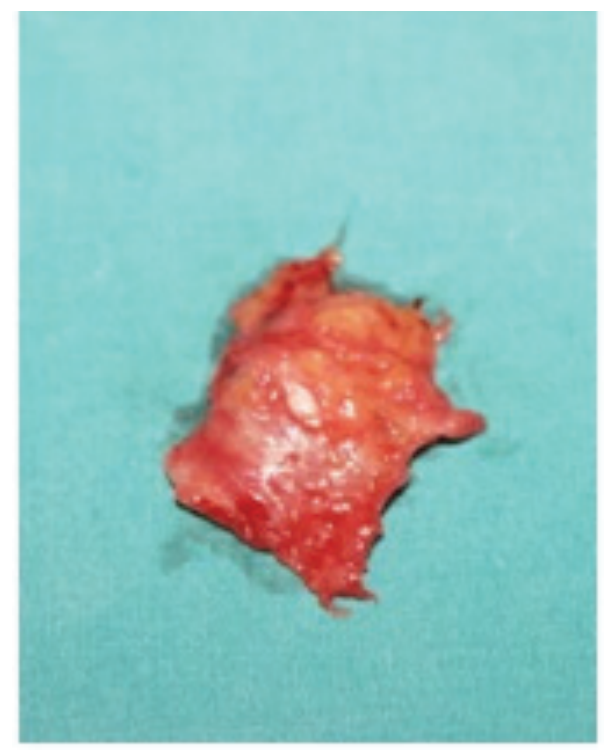

Figure 4. Excised anterior capsule 
triceps elevation technique rather than splitting it. Hertel et al. (20) have described a sequential arthrolysis which starts with the standard O-K method and continued with a limited lateral and a limited medial approach if needed for adequate release. Posterior incisions or anterior incisions to address the heterotopic bones can also be used. In our experience, we have found lateral or medial approach useful if the olecranon and its fossa have to be reshaped due to osteophyte formation. Neither O-K method nor UHA was needed in our cases.

For long-standing contractures of the elbow, muscle tightness would also restrict motion and Bhattacharya have suggested triceps and brachialis muscle mobilization as a solution, but this will result in loss of strength and will risk the necessary postoperative rehabilitation program and must be avoided if possible (12). It is also important to preserve the primary constraints of the elbow to avoid laxity and the need for an external fixator device. We did not apply any external fixator to our patients.

If severe arthrosis is the cause of stiffness, releasing the soft tissues would improve the ROM but unfortunately the pain would continue being the most important complaint of the patient and he or she would seek the preoperative condition of the elbow. Therefore, it is important to realize this condition and perform other types of operations like arthrodesis, distraction with fascial interposition arthroplasty or total elbow arthroplasty, which should only be used in some selected patients $(13,21,22)$. Our patient population did not have severe arthrosis; therefore, contracture releases were found to be enough.

Lindenhovius et al. (23) stated that the release in elbows with $\mathrm{HO}$ would have better results than the stiff elbows without $\mathrm{HO}$. Our results with $\mathrm{HO}$ resections support this statement. In case of total bony ankylosis, the muscle control and strength must be carefully evaluated as these patients would lose the gained arc if they cannot actively flex or extend their elbows after releasing the stiffness.

In a report by Liu et al. (24), the mean improvement in total elbow flexion/extension motions was 80 degrees documented in 11 patients by using combination of lateral and medial approaches and hinged external fixation. In another study performed by Ehsan et al. (25), he documents a total improvement of 58 degrees of elbow flexion/extension motions. Of interest, 68 of 77 patients demonstrated radiographic evidence of $\mathrm{HO}$ and 53 patients (69\%) achieved a total arc of motion $\geq 100$ degrees. Another report by Kayalar et al. (26) represents an increase of 66 degrees in total flexion/extension arc. The average increase in our study was 67.8 degrees (30-125 degrees), which is comparable with others.

The post-operative physical therapy program of these patients is of paramount importance because maintenance of the gained ROM will affect the overall results. Unfortunately, there is no consensus about the most effective therapy program in the literature (6). Some authors have used immediate postoperative continuous passive motion (CPM), interscalene blocks and corrective splinting modalities but some authors did not ever 
use the CPM $(5,15,23,24)$. In our clinic, we use static splinting for the first post-operative day in an elevated position to decrease the soft tissue swelling, and the position of the elbow in the long arm splint depends on the patient's preoperative findings. If the operation was performed for a flexion contracture with or without lack of flexion, the elbow was splinted in maximal extension position that was gained in the operation room. If the aim was to gain only flexion, the position of the splint was set in flexion. We believe that educating the patient about passive exercises is a very effective method if he/she is compatible and capable of using his/her other upper extremity. After 24 hours, the patient begins passively flexing the elbow to the end point and stands in that position for fifteen minutes. After muscle relaxation, the patient can flex the elbow a little bit more and holds that position for another 15 minutes. Then does the same for extension exercises and wears the splint when got tired. The splints are worn every resting time and after three weeks worn only nightly. Indwelling brachial plexus catheter was used for pain management during the therapy program for two days and followed by non-steroidal anti-inflammatory agents. Indomethacin $25 \mathrm{mg}$ three times daily was preferred if there were ectopic bones.

Charalambous and Morrey (8) emphasized the importance of molecular pathogenesis of the stiffness in a review of posttraumatic elbow stiffness. In a study conducted by Hildebrand et al. (27), anterior capsules of contracted elbows and healthy elbows of organ donors were compared and immunohistochemical study revealed that myofibroblast numbers were significantly elevated in the contracted elbow capsules. Cohen et al. (28) also investigated the contracted capsules and compared to normal capsules of donors and demonstrated that the contracted capsules were thicker and cytokine levels (MMP-1, MMP-2 and MMP-3) were significantly higher than normal capsules, while collagen type III had decreased levels. According to these findings, they stated that the contracture tissue formation mechanism was different than normal wound healing. Hildebrand et al. (9) also assessed joint myofibroblasts, nerve fibers containing neuropeptides and mast cells by immunohistochemistry in another study and found significantly greater expression in the contracture capsules. They suggested that a manipulation to myofibroblast-mast cellneuropeptide fibrosis link should be a solution which warrants further investigation.

Molecular pathogenesis of the stiffness is still under investigation and immunohistochemical studies warrants further investigation.

\section{CONCLUSION}

Although good results can be achieved by open release of the stiff elbows, one must keep in mind that preventing the stiffness rather than solving this problem would bring better results. As 15 patients with stiff elbows among the 23 patients included in our study had a previous surgery performed for an elbow region fracture, we may conclude that stable fixation, meticulous hemostasis, minimal immobilization and early rehabilitation must be achieved for avoiding elbow stiffness where surgical treatment is indicated.

However, any patient with elbow trauma must be informed about the possibility of stiffness. And, we believe that the basic scientific investigations should focus on the prophylaxis of joint stiffness in the future.

Ethics Committee Approval: Ethics committee approval was received for this study from the ethics committee of University of Health Sciences Turkey, Gaziosmanpaşa Training and Research Hospital (approval number: 125; date: 16.01.2019).

Informed Consent: It was obtained.

Peer-review: Externally peer-reviewed.

Author Contributions: Concept - E.Ö., K.Ö., S.A.; Design - B.B.D., M.D., A.U.G.; Supervision - B.B.D., M.D., A.U.G.; Resources- B.B.D., M.D., A.U.G.; Materials - K.Ö.; Data Collection or Processing - E.Ö., K.Ö., S.A.; Analysis or Interpretation - E.Ö.; Literature Search - S.A.; Writing Manuscript - E.Ö.; Critical Review - E.Ö., K.Ö., S.A.

Conflict of Interest: The authors have no conflict of interest to declare.

Financial Disclosure: The authors declared that this study has received no financial support.

\section{REFERENCES}

1. Morrey BF, Askew LJ, Chao EY. A biomechanical study of normal functional elbow motion. J Bone Joint Surg Am 1981; 63: 872-7.

2. de Haan J, Schep NW, Tuinebreijer WE, Patka P, den Hartog D. Simple elbow dislocations: a systematic review of the literature. Arch Orthop Trauma Surg 2010; 130: 241-9.

3. Bryce CD, Armstrong AD. Anatomy and biomechanics of the elbow. Orthop Clin North Am 2008; 39: 141-54.

4. Mansat P, Morrey BF. The column procedure: a limited lateral approach for extrinsic contracture of the elbow. J Bone Joint Surg Am 1998; 80: 1603-15.

5. Chuinard C. The stiff elbow. Current Orthopaedic Practice 2008; 19: 6027.

6. Davila, SA, Johnston-Jones, K.: Managing the stiff elbow: operative, nonoperative, and postoperative techniques. J Hand Ther 2006; 19: 26881 ,

7. Nandi S, Maschke S, Evans PJ, Lawton JN. The stiff elbow. Journal of Hand Surgery 2009; 4: 368-79.

8. Charalambous CP, Morrey BF. Posttraumatic elbow stiffness. J Bone Joint Surg Am 2012; 94: 1428-37.

9. Hildebrand KA, Zhang M, Salo PT, Hart DA. Joint capsule mast cells and neuropeptides are increased within four weeks of injury and remain elevated in chronic stages of posttraumatic contractures. J Orthop Res 2008; 26: 1313-9.

10. Barron OA, Catalano LW. The stiff elbow: Diagnosis and treatment. Curr Opin Orthop 2002; 13: 323-327.

11. Tosun B, Gundes H, Buluc L, Sarlak AY. The use of combined lateral and medial releases in the treatment of post-traumatic contracture of the elbow. Int Orthop 2007; 31: 635-8.

12. Garg B, Dua A, Sharma V. Stiff elbow. Pb Journal of Orthopaedics 2009; 11.

13. Morrey BF. Post-traumatic contracture of the elbow. Operative treatment including distraction arthroplasty. J Bone Joint Surg Am 1990; 72: 601-18.

14. Ball CM, Meunier M, Galatz LM, Calfee R, Yamaguchi K. Arthroscopic treatment of post-traumatic elbow contracture. J Shoulder Elbow Surg 2002; 11: 624-9.

15. Tucker SA, Savoie FH, O'Brien MJ. Arthroscopic management of the post-traumatic stiff elbow. J Shoulder Elbow Surg 2011; 20: 83-9.

16. Peden JP, Savoie FH. Arthroscopy of the Stiff Elbow. Techniques in orthopaedics. surgical management of complex elbow problems: Update 2006; 21: 331-9.

17. Mansat P, Morrey BF, Hotchkiss RN. Extrinsic contracture: the column procedure, lateral and medial capsular releases. In Morrey BF, ed. The 
Elbow and Its Disorders, 3rd ed. Philadelphia: WB Saunders, 2000:44756.

18. Vingerhoeds B, Degreef I, De Smet L. Debridement arthroplasty for osteoarthritis of the elbow (Outerbridge-Kashiwagi procedure). Acta Orthop Belg 2004; 70: 306-10.

19. Morrey BF. Primary Degenerative arthritis of the elbow treatment by ulnohumeral arthroplasty. J Bone Joint Surg Br 1992; 74: 409-13.

20. Hertel R, Pisan M, Lambert S, Ballmer F. Operative management of the stiff elbow: sequential arthrolysis based on a transhumeral approach. $J$ Shoulder Elbow Surg 1997; 6: 82-8.

21. Wang J, Li H, Zheng Q, Feng G, Li J, Pan Z. Distraction arthrolysis of posttraumatic elbow stiffness with a hinged external fixator. Orthopedics 2012; 35: e1625-30.

22. Forthman CL, Jupiter JB. Surgical Approach to the Posttraumatic Stiff Elbow. Techniques in Shoulder \& Elbow Surgery 2004; 5: 219-230.

23. Lindenhovius AL, Linzel DS, Doornberg JN, Ring DC, Jupiter JB. Comparison of elbow contracture release in elbows with and without heterotopic ossification restriction motion. J Shoulder Elbow Surg 2007; 16: 621-5.

24. Liu S, Fan CY, Ruan HJ, Li FF, Tian J. Combination of arthrolysis by lateral and medial approaches and hinged external fixation in the treatment of stiff elbow. J Trauma 2011; 70: 373-6.

25. Ehsan A, Huang JI, Lyons M, Hanel DP. Surgical management of posttraumatic elbow arthrofibrosis. J Trauma Acute Care Surg 2012; 72: 1399-403.

26. Kayalar M, Ozerkan F, Bal E, Toros T, Ademoğlu Y, Ada S. Elbow arthrolysis in severely stiff elbows. Arch Orthop Trauma Surg 2008; 128: 1055-63.

27. Hildebrand KA, Zhang $M$, van Snellenberg W, King GJ, Hart DA. Myofibroblast numbers are elevated in human elbow capsules after trauma. Clin Orthop Relat Res 2004; 189-97.

28. Cohen MS, Schimmel DR, Masuda K, Hastings $H$, Muehleman C. Structural and biochemical evaluation of the elbow capsule following trauma. J Shoulder Elbow Surg 2007; 16: 484-90. 